Animal Behaviour, 1989, v.37, n.3, p.444-454

ISSN: (print 0003-3472) (online 1095-8282)

doi:10.1016/0003-3472(89)90091-2

http://www.elsevier.com

http://www.elsevier.com/wps/find/journaldescription.cws_home/622782/description\#description

http://www.sciencedirect.com/science?_ob=ArticleURL\&_udi=B6W9W-4F2M5GV-

$19 \mathrm{~T} \&$ _user $=3366836 \&$ _coverDate $=03 \% 2 \mathrm{~F} 31 \% 2 \mathrm{~F} 1989 \&$ rdoc $=1 \&$ \&mt $=$ high $\&$ orig $=$ search $\&$ _sort $=\mathrm{d} \&$ docanchor $=\&$ view $=$ c\&_acct $=C 000058403 \&$ \&version $=1 \&$ _urlVersion $=0 \&$ \&serid $=3366836 \& \mathrm{md} 5=031074682 \mathrm{fc} 2782 \mathrm{bba} 589 \mathrm{fc}$ cc19470f2

C1989 The Association for the Study of Animal Behaviour

\title{
Foraging in a patchy environment: prey-encounter rate and residence time distributions
}

\author{
ELIZABETH A. MARSCHALL, PETER L. CHESSON \& ROY A. STEIN \\ Department of Zoology, The Ohio State University
}

\begin{abstract}
Small bluegill sunfish, Lepomis macrochirus, foraging among patches in the laboratory did not search systematically within a patch; their intercapture intervals did not differ from a model of random prey encounter within a patch. Patch-residence time, number of prey eaten, and giving-up time (time between last prey capture and leaving the patch) were measured for bluegills foraging in two different three-patch 'environments' (a constant environment, in which each patch began with the same number of prey and a variable environment, in which two patches began with low prey density and one patch with high prey density). When compared with three decision rules a forager may use to determine when to leave a patch, the data most closely agreed with predictions from a 'constant residence time' rule. Bluegills responded to changes in the distribution of prey among patches, but not by using different decision rules. There was qualitative, but not quantitative, agreement with a model of random residence times. The total number of prey eaten by a bluegill during a foraging bout was similar to the number predicted from a model of random search and random residence times.
\end{abstract}

In both theoretical and empirical work on foraging, investigators have considered three types of information that foragers may use to decide when to leave a patch of prey: (1) the time elapsed since entering the patch, (2) the accumulated reward since entering the patch, and (3) the present rate of energy gain in the patch. From such information, simple decision rules have been proposed that would allow a forager to approximate optimal patch use (Charnov 1976; Krebs 1978; Howell \& Hartl 1980). In this study, we considered three of the decision rules discussed in Krebs (1973) and Krebs et al. (1974): (1) a constant residence-time rule, where a forager stays in each patch for a constant optimal amount of time; (2) a constant number rule, where a forager leaves a patch after capturing a certain number of prey; and (3) a constant giving-up time rule, where a forager remains in a patch until the time since the last prey capture reaches some threshold level. This threshold time, or giving-up time, should be inversely related to the average capture rate for the environment as a whole.

Iwasa et al. (1981) showed that, in a stochastic system, environments differing in distribution of prey would differ in which of the three strategies would provide results closest to optimal. Their results suggest that if prey is distributed heterogeneously among patches, for example if their distribution is a negative binomial, then the best constant giving-up time rule would yield higher capture rates than the best constant residence-time or constant number rule; however, if prey were more homogeneously distributed, the best constant residence-time or number rule would yield the highest rates. Under these conditions, a constant giving-up time 
could yield the lowest capture rates.

We designed experiments to evaluate these three hypotheses of proximal decisionmaking in foragers and tested the results against a fourth hypothesis, a model of random departure times from patches that precludes the use of any of these decision rules. This fourth possibility means that the animal leaves a patch independent of its experience in the patch. The decision to leave is completely random. In addition, we tested whether foragers adjust to their environments by using different decision rules in environments differing in prey distribution.

In a laboratory study, we used small bluegills, Lepomis macrochirus, foraging for midge fly, Chironomus riparius, larvae distributed among patches of artificial vegetation. Under natural conditions, small bluegills forage within vegetated littoral habitats, and midge fly larvae are a major component of their diets (Werner 1967; Keast 1978; Mittelbach 1981). We first conditioned bluegills to an environment in which prey were equally distributed among patches. Then, by varying the distribution, we were able to distinguish among the four hypothesized decision rules. We could also determine whether bluegills used a different patch departure rule in environments differing in distribution of prey.

\section{MODELS}

\section{Random Departure Time}

The random depature time 'rule', can be given a precise mathematical description that allows it to be tested. If an animal has been in a patch for some amount of time $t$, then the probability that it leaves during the next time interval, $(t, t+h)$, should depend only on $h$, the length of the interval, and not on $t$, the amount of time already spent in the patch, or on any other information the animal has. In mathematical terms, this means that if $E$ is the exit time from the patch, the conditional probability

$$
P(t<E<t+h \mid t<E \text {, all knowledge before time } t)
$$

should depend only on $h$. This statement can be shown to imply that $E$ has the exponential probability distribution in which

$$
P(E>t)=\mathrm{e}^{-\mu t}
$$

for some positive $\mu$ (Johnson \& Kotz 1970). Note that $1 / \mu$ is the mean of $E$ and the probability density function is

$$
\mathrm{f}(t)=\mu \mathrm{e}^{-\mu t}, t>0
$$

\section{Random Search Within a Patch}

The standard model of random search within a patch commonly used in foraging theory (Murdoch \& Oaten 1975; McNair 1982; McNamara 1982; Stephens \& Charnov 1982; Chesson 1983 ) is also based on the exponential distribution. If $n$ prey are left in a patch, then the time $T_{\mathrm{n}}$ before the next prey encounter has the exponential distribution

$$
P\left(\mathrm{~T}_{n}>t\right)=\mathrm{e}^{-a n t}
$$

where $\alpha$ is some positive constant (Murdoch \& Oaten 1975). In the Appendix this is shown to be equivalent to the following assumptions: (1) each individual prey is encountered and captured independently, such that the time to capture any particular individual is not affected by the 
number of prey present; and (2) the probability of finding a prey during the next interval of time depends only on the length of that interval and not on the amount of unsuccessful search time that has already elapsed. This second assumption leads to the exponential distribution for the time to capture a particular individual prey, and the independence of capture times for different individuals then implies the expression (1). Note that with this model, the mean time to capture the next prey, when $n$ prey are left, is $1 / \alpha n$.

\section{METHODS}

Bluegills, 50-65 mm total length, foraged among patches of artificial vegetation containing prey, in the experiments. Midge fly larvae (10-12 $\mathrm{mm}$ long) that had been frozen, thawed, and attached to the stems with a small amount of aquarium sealant were used as prey. Studies of the food habits of bluegills show them to be capable of eating a wide variety of prey, including benthic, clinging and free-swimming prey (Keast 1978). In the laboratory, they easily learned to eat unfamiliar food and they foraged similarly for these attached midge fly larvae as they did for live damselfly nymphs (Zygoptera), a natural clinging prey.

Patches of artificial vegetation were constructed by attaching green polypropylene rope

stems $\left(3 \mathrm{~mm}\right.$ diameter; $\left.1000 \mathrm{stems} / \mathrm{m}^{2}\right)$ to Plexiglas bases $(40 \times 36 \mathrm{~cm})$ and allowing the free ends to float to the water surface. Each experiment was done in a circular pool (1.75 $\mathrm{m}$ diameter) at $25^{\circ} \mathrm{C}$. A bluegill was satiated with trout chow, starved for $24 \mathrm{~h}$ at $25^{\circ} \mathrm{C}$, and then released into the experimental pool, outside of a patch. Using an event recorder, we recorded the time of each prey capture, the time the bluegill entered a patch, the time it left a patch, and each time it stopped and started searching. Fish were removed from the experimental pool after each foraging bout (one foraging bout $=$ one experiment).

\section{Single-patch Experiments}

To determine the foraging ability of each individual within a patch when it was not permitted to change patches, we ran experiments in which a bluegill was confined to one patch in the pool. An experiment ended when the fish ate all the prey or when it stopped searching for more than $1 \mathrm{~min}$. At least two replicates were done with each of seven fish in each of three prey densities (four, eight, or 16 prey per patch). In these experiments and the experiments that follow, we analysed data from each fish separately.

Observations from the single-patch experiments were used to test the model of random search within a patch. According to this model, $n T_{\mathrm{n}}$ (prey density $\times$ intercapture interval) should have an exponential distribution with constant parameter $\alpha$ (Appendix). We tested exponentiality assuming constancy of the parameter, and tested constancy of the parameter assuming exponentiality. While not a perfect inferential procedure, it can be done with existing tests and is likely to give high power to both tests.

Exponentiality of capture times was tested separately for each fish using the statistic $\mathrm{W}_{n}^{2}$ (Pearson \& Stephens 1962; Seshadri et al. 1969). Conclusions of exponentiality were based on the assumption that $n$ (prey density) was not affecting $n T_{\mathrm{n}}$ systematically. To test this, we used Bartlett's statistic which is designed for testing differences between variances for normally distributed data. However, it can also be used for testing differences in distribution for exponentially distributed data because exponential random variables are proportional to $\chi^{2}$ random variables with two degrees of freedom (Johnson \& Kotz 1970). Assuming the $n T_{\mathrm{n}}$ to be exponential, we used Bartlett's statistic to compare distributions of $n T_{\mathrm{n}}$ over different values of $n$.

Handling times, when present, and non-searching times (times when bluegills were not 
swimming) were subtracted from all measures of time in the experiments, so that data were analysed with respect to search time, rather than total time. In general, handling times were too small to be measurable by direct observation; only occasionally did we observe bluegills actively manipulating prey. In plotting the data from the single-patch experiments, however, we found that all fish exhibited a similar deviation from the exponential distribution, implying that some small constant amount of time was associated with each prey. By reviewing films taken earlier of different bluegills of the same size $(50-60 \mathrm{~mm})$, we found a 'recovery time' $(\bar{X} \pm \mathrm{SD}=0.03 \pm$ $0.01 \mathrm{~min}, N=21$ observations) after each prey capture. A bluegill would eat a prey off a stem, then back away from the stem and stop before beginning to search again. To adjust for this, we subtracted $0.03 \mathrm{~min}$ from all search times following prey captures. All subsequent references to intercapture intervals, giving-up times, and residence times exclude recovery and active handling times.

\section{Multiple-patch Experiments}

To examine behaviour of bluegill foraging in a patchy environment, we used three patches of artificial vegetation in the pool. We followed the procedures described above for single-patch experiments, except that each foraging bout was ended after $3 \mathrm{~min}$. Each of seven bluegills was presented with two types of environments, each having a total of 24 prey distributed over three patches. The first type (constant environment) had eight prey in each patch at the start of an experiment. In the second type (variable environment), one patch had 16 prey and the other two each had four prey. Before beginning the actual sequence of experiments, each fish was required to have three 'successful' trials in the constant environment. To be considered 'successful' in a trial, a bluegill had to search, eat prey, and change patches at least once. We did not use data from these initial trials in our analyses. The experimental sequence consisted of at least six foraging bouts in the constant environment (six-nine bouts depending on the individual), followed by $10-17$ bouts in the variable environment, with two final bouts in the constant environment.

The first sequence of bouts (all in a constant environment), were preceded by the three training bouts in a constant environment and so we describe this first sequence of bouts as having had a 'constant conditioning environment' as well as a 'constant current environment'. The first three of the 10-17 bouts in a variable environment had a constant conditioning environment and a variable current environment, whereas the next 7-14 had both a variable conditioning environment and a variable current environment. The final two bouts in the constant environment had a variable conditioning environment and a constant current environment. These assignments assume that conditioning fish to a new environment takes no longer than three foraging bouts. We repeated this entire sequence with each of the seven bluegills.

The three decision rules can be assessed by correlations between the number of prey in a patch at the start of a visit and each of the three measures of patch use (residence time, number of prey eaten and giving-up time). We calculated Spearman's rank correlation statistic $r_{\mathrm{ij}}$ for each bluegill (indicated by i) and each foraging bout (experiment, indicated by j). These were then combined into an overall statistic, $Z$, having a standard normal distribution under the null hypothesis of no correlation. The formula for $Z$ is 


$$
Z=\frac{\sum_{i j}^{m_{j}}\left(n_{i j}-1\right) r_{i j}}{\sqrt{\sum_{i}^{m_{j}}\left(n_{i j}-1\right)}}
$$

where $m_{\mathrm{i}}$ is the total number of experiments for fish $\mathrm{i}$ and $n_{\mathrm{ij}}$ is the number of observations in experiment $\mathrm{j}$ for fish $\mathrm{i}$. This formula follows from the fact that the $r_{\mathrm{ij}}$ are independent and asymptotically normal with mean zero and variance on $1 /\left(n_{\mathrm{ij}}{ }^{-1}\right)$ under the null hypothesis (Kendall 1962). We calculated this summary statistic $Z$ for each measure of patch use for each environment (constant or variable).

In addition to analysing patch use as a response to prey density, we tested whether bluegills adjusted their behaviour in reponse to expectations of prey distribution. If bluegills learn about the environment while foraging in it and change their behaviour in response to what they have learned, then, for example, a bluegill foraging in a variable environment may use different patch-departure rules if it has been conditioned to that variable environment than if it is expecting a constant environment. We tested for this using a Wilcoxon signed-rank test (Hollander \& Wolf 1973), pairing data from treatments having the same current environment but differing in conditioning environment. For each individual bluegill, within a current environment, we paired observations from patch visits having equal prey densities, in order of their occurrence within experiments, between the two conditioning environments. We used relative differences, defined as the difference in the logarithms of the paired observations. After pairing observations for individual fish, we pooled the relative differences from all fish before ranking them, to determine a general effect of conditioning environment.

\section{RESULTS}

\section{Single-patch Experiments}

In testing exponentiality of capture times, we found the distribution of $n T_{n}$ did not differ significantly from the exponential distribution for six of seven fish $(P>0.05$ for all six fish; see Fig. 1 for data from one fish). The remaining fish had a distribution of $n T_{n}$ that differed significantly $(P<0.05)$ from the exponential. To determine if this one significant result should be regarded as true significance, given that multiple comparisons were being made, we used Bonferroni's inequality (Kotz et al. 1982, page 295). Based on this inequality, a single test among seven should be considered significant at the 0.05 level if the test by itself gives significance at the $0.05 / 7$ level. Because the minimum value of $P$ was greater than $0 \cdot 05 / 7$, we concluded that, in general, $n T_{n}$ could not be distinguished from the exponential distribution.

Using Bartlett's statistic, we tested for constancy of the parameter of the exponential distribution by comparing distributions of $n T_{n}$ over different values of $n$. For six of seven fish, the distribution of $n T_{n}$ was the same over all $n(P>0.05)$, but for the remaining fish, $0.01<P<$ 0.025. (This was not the same fish that differed in the previous test.) A combined $P$-value (Fisher's method, Sokal \& Rohlf 1981, page 780) for all the fish was greater than 0.05. Thus, it appears that the second part of the random search model, constancy of the distribution of $n T_{n}$ as $n$ varies, cannot be rejected by these data. 


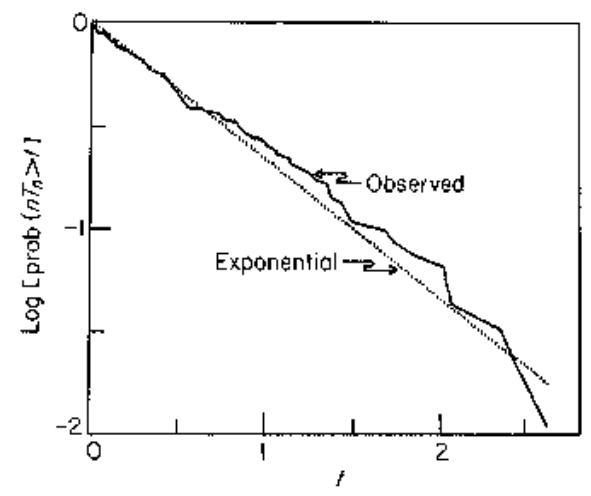

Figure 1. Logarithm of the probability distribution of prey density $(n)$ times intercapture interval $\left(T_{n}\right)$ for an individual bluegill. The solid line represents the actual distribution and the dotted line represents the theoretical exponential distribution with mean equal to the actual mean.

\section{Multiple-patch Experiments}

Data from the sequence of three-patch experiments were compared with predictions from each of the three proposed patch-departure rules. For each rule, we specified how each of three measures of patch use (residence time, number of prey eaten and giving-up time) should be correlated with patch value (patch value = prey density in the patch at beginning of a visit). (1) With a constant residence-time rule, residence times should not be correlated with patch value (by definition); however, the number of prey eaten per visit should increase with increasing patch value. If a bluegill leaves each patch after the same amount of foraging time, then the reward rate immediately before leaving should be correlated positively with initial prey density. Consequently, the time between the last capture and patch departure (giving-up time) will be correlated negatively with initial prey density. (2) If bluegills use a constant number rule, they should require little time in patches having high prey density, so we would expect residence times to be correlated negatively with patch value. In this case, neither number of prey eaten (by definition) nor giving-up time should be correlated with prey density. (Foragers should leave shortly after the last prey capture, so giving-up time should be small in all patch visits.) (3) With a constant giving-up time rule, bluegills should spend more time and capture more prey in high prey density patches than in low prey density patches, so both residence time and number of prey eaten should be correlated positively with prey density. Giving-up time should not be correlated with prey density.

In analysing data, we included only complete patch visits (those that had both an entrance and leaving time). The last patch visit was often not included because it was incomplete, i.e. it had no leaving time, ending with the fish still in a patch. During the three-patch experiments, it became obvious that one of the seven fish was behaving quite differently from the other six fish. (This was not the same individual that differed in either of the tests in the single-patch experiments.) This fish tended to have fewer patch visits per foraging bout ( $3 \cdot 1$ visits/bout) than the other six fish (6.3 visits/ bout). In the first two foraging bouts in the variable environment, this fish had only one complete patch visit in a high-density patch and one in a low-density patch (recall that, for a 'complete' visit, a fish must enter and leave a patch). Consequently, sample sizes were too small to compare behaviour among prey densities as we had for the other six fish. Although enough visits occurred to permit a few statistical comparisons, the proportion of patch visits that were not included because they were incomplete (one out of four visits) was too large 
to allow these to be representative of this bluegill's behaviour. Thus, we did not include data from this bluegill in the following analyses.

Table I. Weighted mean rank correlations between patch quality (density of prey at beginning of visit) and three measures of patch use for each fish in the constant environment

\begin{tabular}{|c|c|c|c|c|c|c|c|c|}
\hline & \multicolumn{7}{|c|}{ Fish } & \multirow[b]{2}{*}{$P$} \\
\hline & 1 & 2 & 3 & & 4 & 5 & 6 & \\
\hline \multicolumn{9}{|c|}{ (A) Conditioned to constant environment } \\
\hline $\begin{array}{l}\text { Residence time } \\
\text { Number eaten } \\
\text { Giving-up time }\end{array}$ & $\begin{array}{c}-016 \\
0-38 \\
-0-65\end{array}$ & $\begin{array}{ll}- & -0-24 \\
& 0-76 \\
& -0-65\end{array}$ & $\begin{array}{r}-0-27 \\
0-73 \\
-0-59\end{array}$ & - & $\begin{array}{r}-0-46 \\
0-74 \\
-0-34\end{array}$ & $\begin{array}{r}001 \\
0-67 \\
-0-40\end{array}$ & $\begin{array}{r}-0-28 \\
0-72 \\
-0-59\end{array}$ & $\begin{array}{l}<0-001 \\
<0-001 \\
<0-001\end{array}$ \\
\hline \multicolumn{9}{|c|}{ (B) Conditioned to variable environment } \\
\hline $\begin{array}{l}\text { Residence time } \\
\text { Number eaten } \\
\text { Giving-up time }\end{array}$ & $\begin{array}{c}100 \\
-100 \\
100\end{array}$ & $\begin{array}{ll}- & -019 \\
& 0-67 \\
- & -0-33\end{array}$ & $\begin{array}{r}-0-76 \\
0-67 \\
-0-78\end{array}$ & - & $\begin{array}{r}-0-25 \\
0-97 \\
-0-87\end{array}$ & $\begin{array}{r}-0-21 \\
0-54 \\
-0-57\end{array}$ & $\begin{array}{r}-0-42 \\
0-17 \\
-0-58\end{array}$ & $\begin{array}{r}0-005 \\
<0-001 \\
<0-001\end{array}$ \\
\hline
\end{tabular}

Probabilities are based on correlations combined as described in the text.

\section{Patch-departure rules within treatments}

We first analysed the two treatments in which the current environment was the same as the conditioning environment. In these treatments, ranks of number of prey eaten were correlated positively and ranks of giving-up times were correlated negatively with ranks of prey density in both environments, for all fish (Tables IA and IIB). In the variable environment, ranks of residence times were not correlated with ranks of prey density, but in the constant environment, these were correlated negatively. In this environment, only patches containing eight prey were available at the beginning of an experiment and any revisits to patches resulted in lower prey densities, so the effects of prey density and order of patch visit could not be separated.

In the variable environment, results (Table IIB) agreed with qualitative predictions from both the constant residence-time rule and the model of random exit times. To distinguish between these two, we used a $\mathrm{W}_{n}^{2}$ statistic (Seshadri et al. 1969) to compare our observations of residence times with the model of random (exponentially distributed) exit times. For all six fish, distributions of residence times differed significantly from exponential distributions $(P<0.05)$. All six distributions differed from exponential by having minimum residence times greater than 0 . This implied that some minimal amount of time was associated with each patch visit.

This minimum residence time may have been some kind of orientation time required at the beginning of a patch visit. To measure the orientation time, if any, required when entering a patch, we took the difference between the mean time to capture a prey when just arriving in a patch and the mean time to capture a prey later in a patch visit, for each prey density, for each bluegill. For each individual, we averaged these differences across prey densities to arrive at an approximation of orientation time necessary for that individual. Mean values for individuals ranged from -0.02 min to +0.02 min (only one fish had a value less than 0 ). After subtracting these orientation times from residence times, we again compared residence times with the model of random exit times. We found that residence times for all six fish still differed significantly from the exponential distribution $(P<0.05)$. 
Table II. Weighted mean rank correlations between patch quality (density of prey at beginning of visit) and three measures of patch use for each fish in the variable environment

\begin{tabular}{|c|c|c|c|c|c|c|c|}
\hline \multicolumn{8}{|c|}{ Fish } \\
\hline & 1 & 2 & 3 & 4 & 5 & 6 & $P$ \\
\hline \multicolumn{8}{|c|}{ (A) Conditioned to constant environment } \\
\hline Residence time & 0.50 & -0.29 & $-0 \cdot 27$ & -0.06 & $0 \cdot 14$ & $0 \cdot 3$ & $0-37$ \\
\hline Number eaten & $0 \cdot 50$ & 0.61 & 0.73 & $\begin{array}{r}-0.06 \\
0.68\end{array}$ & $\begin{array}{l}0.14 \\
0.71\end{array}$ & $\begin{array}{r}0.3 \\
0.81\end{array}$ & $<0.001$ \\
\hline Giving-up time & -0.08 & $-0 \cdot 70$ & $-0 \cdot 54$ & $\begin{array}{r}0.68 \\
-0 \cdot 15\end{array}$ & $\begin{array}{r}0 . / 1 \\
-0.36\end{array}$ & $\begin{array}{r}0.81 \\
-0.29\end{array}$ & $<0.001$ \\
\hline \multicolumn{8}{|c|}{ (B) Conditioned to variable environment } \\
\hline Residence time & 0.32 & 0.05 & $-0 \cdot 24$ & 0.08 & 0.03 & $0 \cdot 10$ & 0.41 \\
\hline Number eaten & 0.78 & 0.75 & 0.78 & $\begin{array}{l}0.08 \\
0.85\end{array}$ & $\begin{array}{l}0.03 \\
0.77\end{array}$ & $\begin{array}{l}0.10 \\
0.80\end{array}$ & $\begin{aligned} 0.41 \\
<0.001\end{aligned}$ \\
\hline Giving-up time & $-0 \cdot 16$ & -0.58 & -0.59 & $\begin{array}{r}0.85 \\
-0.30\end{array}$ & $\begin{array}{r}0 \cdot / 1 \\
-0 \cdot 36\end{array}$ & -0.53 & $<0.001$ \\
\hline
\end{tabular}

Probabilities are based on correlations combined as described in the text

\section{Response to expectations of prey distribution}

In addition to analysing patch use as a response to prey density, we tested whether bluegills adjusted their behaviour in response to expectations of prey distribution. For a bluegill foraging in the constant environment, statistical significance and signs of Spearman's rank correlations between patch quality and the three measures of patch use were the same regardless of the environment the bluegill was expecting (Table IA versus IB). Similarly, for a bluegill foraging in the variable environment, signs and significance of correlations were consistent with a constant residence time rule, regardless of the environment it was expecting (Table IIB versus IIA).

Using Wilcoxon signed-rank tests to determine the quantitative effect of conditioning environment on the three measures of patch use, we found no consistent effect of either of the two types of conditioning environment (Table III). However, the data did show a trend in the direction of shorter residence times and giving-up times and fewer prey eaten per visit when the current environment differed from the conditioning environment.

\section{Comparison to random departure}

To evaluate whether bluegills were using patches in a way that permitted them to increase the total number of prey eaten, relative to the model of random residence times, we calculated the expected number of prey eaten under the random model and compared it with the mean number eaten per experiment in the first six experiments (constant environment). Because we knew the distribution of search times between captures within a patch for each bluegill, and the random residence model specifies the distribution of residence times, we could calculate the expected number of prey eaten during an experiment of a particular length (Appendix). Although foraging bouts all lasted $3 \mathrm{~min}$, the amount of time bluegill actually spent searching varied among these bouts. Because the random model would predict different numbers of prey eaten for differing amounts of search time, we used the minimum search time per experiment, over all experiments, for each fish, to represent its search time in an experiment. For the observed value of total number of prey eaten, we counted only those prey captured during this amount of time. The predictions from the model differed for each fish because this model incorporated each individual's average residence time, average intercapture intervals, and minimum duration of foraging bouts. For four of the six fish, the total number of prey captured was greater in the actual experiments than would be expected if bluegills were leaving patches at random, but the other two fish captured fewer prey than predicted by the random exit model. Using a paired $t$ - 
test, we found that the observed mean total number of prey eaten per experiment did not differ significantly from the mean number predicted from the random residence model $(P>0.5)$.

Table III. Mean differences $(\Delta)$ between observations from treatments having the same current environment but different conditioning environments for each of three measures of patch use

\begin{tabular}{lrrrrrrr}
\hline & $\begin{array}{c}\text { Residence } \\
\text { time (min) }\end{array}$ & \multicolumn{1}{c}{$\begin{array}{c}\text { Number } \\
\text { eaten } \\
\text { (prey) }\end{array}$} & \multicolumn{2}{c}{$\begin{array}{c}\text { Giving-up } \\
\text { time (min) }\end{array}$} \\
\cline { 2 - 8 } Treatment & $\Delta$ & $P$ & $\Delta$ & $P$ & $\Delta$ & $P$ \\
\hline CC-VC & $0-21$ & $<0-001$ & $0-66$ & $0-373$ & $0-08$ & $<0-001$ \\
VV-CV & $0-08$ & $0-057$ & $0-69$ & $<0-001$ & $0-04$ & $0-764$ \\
\hline
\end{tabular}

Probabilities are based on Wilcoxon signed-rank tests based on data from all fish and all prey densities, as described in the text. Treatments are indicated by a combination of two letters, C (constant environment) and V (variable environment). The first letter of each pair represents the conditioning environment and the second represents the current environment.

\section{DISCUSSION}

We have shown that bluegill foraging behaviour within a patch agrees with the predictions of the standard model of random search (Murdoch \& Oaten 1975; McNair 1982; McNamara 1982; Stephens \& Charnov 1982; Chesson 1983). The mean capture rate under this model is a linear functional response when considering search times only. With inclusion of handling times, it becomes a Holling type II response.

There are two equivalent ways of expressing the random search model. First, each prey can be considered to be encountered independently in time. The time between entering the patch and catching any given prey is a random variable having an exponential probability distribution, which is the same for every prey (i.e. a priori, no reason exists for any one prey to be caught before any other). The second, but equivalent, way of expressing the model is the one most commonly used in the literature. In it, the emphasis is on the times between prey captures. These intercapture intervals are statistically independent and exponentially distributed, but the mean increases as prey are depleted. Specifically, the mean is inversely proportinal to the number of prey left.

The random search model has often been used in ecology, but is not always expressed in the precise form used in our analysis. For example, the Nicholson \& Bailey (1935) hostparasitoid model, with its Poisson distribution of ovipositions on any given host, has behind it the essence of this random search model. However, random search is often not interpreted accurately in terms of the behaviour of the organisms. For example, both Nicholson \& Bailey (1935) and Murdoch \& Oaten (1975) assume that foragers travel on a smooth path, within a patch. Unless prey are constantly redistributing themselves randomly within a patch, this is unlikely to be compatible with the random search model. A forager changing direction at random can also disagree markedly with the random search model, even though such behaviour is a common intuitive meaning of random search.

What is the behavioural interpretation of our model of random search, described by the exponential probability distribution of capture times for an individual prey? One intepretation is that prey constantly, independently and randomly redistribute themselves about the patch. In our experiments, prey could not redistribute themselves. An alternative set of assumptions is that 
over very short intervals of time, the forager moves to different parts of the patch chosen completely at random, and attempts to capture a prey upon seeing it. The probability that the forager sees any two prey simultaneously must be negligible for independent capture times for different prey. Patches in our experiments were small enough that bluegills could move quickly to any part of the patch and prey were concealed enough in the vegetation that bluegills did not appear to be seeing more than one prey at a time; thus, this interpretation of random movement could quite possibly describe the behaviour of bluegills in our experiments. A third alternative is some combination of the preceding two, resulting in continual random change in the relative locations of both forager and prey. Thus, the model is really one of random encounter, not necessarily random search.

With the random search model, capture rate must decrease as prey are depleted in a patch. This is an important assumption of Charnov's (1976) marginal value model. However, many animals have been shown to search patches systematically, as assumed in Green's models (1980, 1984), and therefore do not experience this effect of prey depletion (ovenbirds, Seiurus aurocapillus, Zach \& Falls 1976; bumble bees, Bombus atratus, Hartling \& Plowright 1979; downy woodpeckers, Picoides pubescens, Lima 1983, 1984). With systematic search, a patch retains the same effective prey density until the forager searches the entire patch and begins to re-search it. With this type of search, a forager's assessment of patch quality can become more accurate as it spends more time and captures more prey in the patch. With random search, the forager experiences a decreased prey density with every prey captured and so must re-assess continually the changing value of the patch based on only one prey capture at any prey density. Because of this, the problem of when to leave a patch may be more complex for a random forager than for a systematic forager.

Lack of systematic search within a patch, as exhibited by bluegills in these experiments, may be adaptive when foraging for certain types of prey. Bluegills of this size are generally found in littoral vegetation feeding on a wide variety of invertebrate prey (Keast 1978; Beard 1982). When present, anti-predator behaviour in aquatic invertebrates frequently consists of becoming motionless or seeking cover in the presence of a predator (Stein \& Magnuson 1976). Although actual prey density does not change, effective prey density in that area is depressed when prey respond in this way (Charnov et al. 1976). Because prey moving or not concealed are easiest to find and capture (Ware 1973; Crowder \& Cooper 1982), a forager would do better (would be more likely to encounter moving prey) by searching away from the immediate area of the last capture where the prey have already had time to respond to the predator. In this situation, then, systematically searching from one end of the patch to the other may not yield the optimal result. In contrast, in systems having discrete patches and no strong anti-predator behaviour by prey (or other food items), such as woodpeckers foraging for insects on trees or bumble bees foraging for nectar in flowers, some type of systematic search within each patch may be favoured.

Although many investigators have found foragers to be using some type of capture rate or giving-up time strategy (chickadees, Parus atricapillus, Krebs et al. 1974; great tits, Parus major, Cowie 1977; Ydenberg 1984; hummingbirds, Selasphorus spp., Pyke 1978; caddisfly larvae, Plectrocnemia conspersa, Townsend \& Hildrew 1980), the optimal strategy may actually differ under different conditions. Evaluating the same three decision rules that we considered, Iwasa et al. (1981) showed that a forager would do best in a constant environment by choosing an optimal constant residence time or an optimal constant number of prey to eat per patch, and would do best in a variable environment by choosing an optimal constant giving-up time rule. 
Stewart-Oaten (1982) found that, when prey distribution is Poisson, foragers can maximize their intake using a constant residence time rule. In our experiments we did not find a distinct change in patterns of patch use with a change in prey distribution; rather, measures of giving-up time, number of prey eaten, and residence time generally agreed with predictions from a constant residence-time rule in both environments (although this analysis was confounded by order of patch visits in the constant environment). Although the general pattern of patch use did not change, we did find bluegills responding to a new environment by spending more time, eating more prey, and having longer giving-up times in early patch visits in the new environment than when conditioned to that environment. The ability to respond quickly to changes in food distribution is obviously important in dealing with daily, seasonal, and unpredictable changes in resources.

Other theory shows that the optimal strategy in an environment with patches of different values (i.e. different prey densities) is to persist in high-value patches (McNair 1982). The forager should allow long giving-up times in patches it knows to have high prey densities. Bluegills in our experiments did just the opposite: they had shorter giving-up times in high-value patches than in low-value patches, probably because they were unable to assess the value of a patch without sampling it. This was not surprising, because not only did we attempt to make patches appear identical, but we also changed their relative positions from one foraging bout to the next so that bluegills would not be expecting a particular patch to have a particular prey density. Experiments were designed under the assumption that, in nature, bluegills (and many other foragers) are probably not able to distinguish the value of a patch before foraging in it and must base decisions of patch quality on encounter rates with prey

Bluegills had residence times that tended to be more constant than predicted by the random model which is consistent with the notion that they are using some kind of decision rule. However, the most important measure of foraging success (i.e. total number of prey eaten) revealed that their behaviour was no more profitable than leaving patches at random.

Using simple mathematical models to represent our null hypotheses of several aspects of patch-use behaviour, we compared our data directly with random prey-encounter rates, random patch-departure times, and the resulting total number of prey captured during a foraging bout of given length. We found that the frequently made, but rarely tested, assumption of random preyencounter rates was reasonable in this system. Comparing several measures of patch use by bluegills with qualitative representations of previously described patch-departure rules, we found that use of patches by bluegills was most consistent with a constant residence time patchdeparture rule and differed from random patch-departure times. However; even with this tendency toward constancy in residence times, bluegills ultimately were no more successful than if they had left patches completely at random. This emphasizes that it is important not only to assess behavioural trends in foraging studies, but also determine the value of the behaviour by comparing results with quantitative models that assume no such behaviour.

\section{APPENDIX}

\section{Random Search Within a Patch}

The model of random search within a patch is based on two assumptions. First, each individual prey is encountered and captured independently, such that time to capture any particular individual is not affected by the number of prey present. Although this assumption may at first seem unreasonable, it is not if prey have negligible handling time. As a consequence, the probability distributions of capture times for each prey are independent and identically 
distributed. The second assumption is that the probability of finding a prey during the next interval of time depends only on the length of that interval and not on the amount of unsuccessful search time that has already elapsed. These assumptions lead to capture times having an exponential distribution

$$
P\left(U_{\mathrm{i}}>t\right)=\mathrm{e}^{-\alpha t}
$$

where $U_{\mathrm{i}}=$ time to capture a particular prey i and $\alpha=1 /($ mean time to capture a prey). Given a patch with $n$ prey, the time until the first prey capture, $T_{n}$, in that patch, is the minimum of ( $U_{1}$, $\left.U_{2} \ldots, U_{n}\right)$ and is exponential with mean $1 /(\alpha$ n) (Johnson \& Kotz 1970, page 214). Indeed it is not difficult to see that the times between prey captures are independent exponential random variables with means $1 /(\alpha n), 1 / \alpha(\mathrm{n}-1), 1 / \alpha(n-2), \ldots, 1 / \alpha$.

To obtain a powerful test of this model, we used the fact that if $T_{n}$ is exponential with mean $1 /(\alpha n)$ then $n T_{n}$ is exponential with mean $1 / \alpha$. This allowed us to combine the data for different values of $n$, for each fish.

To summarize, if $U_{\mathrm{i}}$ are distributed exponentially with mean $1 / \alpha$, then $T_{n}$ has an exponential distribution with mean $1 /(\alpha n)$, and $n T_{n}$ is also distributed exponentially with mean $1 / \alpha$. Moreover, this applies whether the fish has just entered a patch with $n$ prey, or has just captured a prey which results in there being $n$ prey left in the patch. These different capture times are independent for any given fish.

\section{Expected Total Number of Prey Eaten}

To calculate the expected value of the total number of prey eaten per experiment under the model of random residence times, we used the exponential distribution of capture times within a patch

$$
P(T>t)=\mathrm{e}^{-\alpha t}
$$

where $\alpha$ is $1 /$ (mean time to capture a particular prey). The total number of prey eaten in each patch during an experiment is related simply to the total time spent in that patch (including revisits to the patch). If an experiment runs for $t$ time units, the total time spent searching in patch $i$ can be expressed as

$$
S_{i}=\int_{0}^{1} 1_{\{x(u)=i\}} \mathrm{d} u
$$

where $X(u)$ is the patch in which the bluegill is searching at time $u$, and $1_{\mathrm{A}}$ is the indicator function of the set A. ( $1_{\mathrm{A}}=1$ when A occurs, and is zero otherwise.) The bluegill has $S_{i}$ units of time to capture a particular prey in patch $i$. Given $S_{i}$ the probability of not capturing a particular prey in patch $i$ is $\mathrm{e}^{-\alpha S i}$. If $\emptyset_{i j}(t)$ is the probability of not capturing this prey given that the bluegill starts in patch $j$, then

$$
\phi_{i, j}(t)=\mathrm{E}\left[\mathrm{e}^{-\alpha S_{i}} \mid \overline{X(0)}=j\right]
$$

We assume that the patch in which bluegill start is chosen randomly so that the probability of a particular prey in patch $i$ not being captured is 


$$
\mathrm{E}\left[\mathrm{e}^{-\alpha . S_{i}}\right]=(1 / 3) \sum_{j=1}^{3} \phi_{i, j}(t)
$$

Letting $i=1$, the probability of a particular prey not being captured in time $t$ plus a small increment of time $h$ is

$$
\begin{gathered}
\phi_{1, j}(t+h)=\mathrm{E}\left[\mathrm{e}^{-\alpha} \int_{0}^{h} 1_{\{, x(u)=1 !} \mathrm{d} u\right. \\
\left.\mathrm{E}\left[\mathrm{e}^{-\alpha} \int_{h}^{h} 1_{\{, x(u)=1:} \mathrm{d} u \mid X(h)\right]\right] \\
=\mathrm{E}\left[\mathrm{e}^{-\alpha} \int_{0}^{h} 1_{\{x(u)=1:} \mathrm{d} u_{\left.\phi_{1, x(h)}(t)\right]}\right.
\end{gathered}
$$

Based on these expressions, we obtain

$$
\begin{gathered}
\phi_{1,2}(t+h)=\mathrm{e}^{-\mu h} \phi_{1,2}(t)+\frac{1}{2} \mu h \phi_{1,3}(t)+\frac{1}{2} \mu h \\
{[1-0(h)] \phi_{1.1}(\mathrm{t})+o(h)}
\end{gathered}
$$

where $\mu$ is the parameter of the exponential distribution of residence times. This expression yields the differential equation

$$
\frac{\mathrm{d} \phi_{1,2}(t)}{\mathrm{d} t}=-\mu \phi_{1,2}(t)+\frac{1}{2} \mu \phi_{1.3}(t)+\frac{1}{2} \mu \phi_{1,1}(t)
$$

Similarly,

$$
\frac{\mathrm{d} \phi_{1,3}(t)}{\mathrm{d} t}=-\mu \phi_{1,3}(t)+\frac{1}{2} \mu \phi_{1.2}(t)+\frac{1}{2} \mu \phi_{1,1}(t)
$$

And

$$
\begin{gathered}
\frac{\mathrm{d} \phi_{1,1}(t)}{\mathrm{d} t}=-(\mu+\alpha) \phi_{1,1}(t)+\frac{1}{2} \mu \\
\phi_{1,2}(t)+\frac{1}{2} \mu \phi_{1,3}(t)
\end{gathered}
$$

Defining the matrix A as

$$
\mathbf{A}=\left[\begin{array}{lll}
-(\mu+\alpha) & \mu / 2 & \mu / 2 \\
\mu / 2 & -\mu & \mu / 2 \\
\mathrm{~m} / 2 & \mu / 2 & -\mu
\end{array}\right]
$$

And $\Phi_{1}(t)=\left[\boldsymbol{\Phi}_{1.1}(t), \boldsymbol{\Phi}_{1.2}(t), \boldsymbol{\Phi}_{1.3}(t)\right]^{\prime}$, equations (A2)-(A4) can be combined as

$$
\frac{\mathrm{d}}{\mathrm{d} t} \boldsymbol{\Phi}_{1}(t)=\mathbf{A} \cdot \boldsymbol{\Phi}_{1}(t)
$$

The solution to this equation is 


$$
\Phi_{1}(t)=\mathrm{e}^{\mathbf{A} / 1}
$$

where $\mathbf{1}=(1,1,1)^{\prime}=\boldsymbol{\Phi}_{1}(0)$ because the probability of not being captured at time 0 equals 1 . Equation (A 1) now implies that the probability that a particular prey in patch 1 is not captured is $(1 / 3) \mathbf{1}^{\prime} \times \boldsymbol{\Phi}_{1}(t)$, which equals (1/3) $\mathbf{1}^{\prime} \mathbf{e}^{\mathbf{A} t} \mathbf{l}$. The expected number of prey left in a patch after time $t$ is the product of this expression and the number of prey present in the patch at the start of the experiment. In these experiments, each of the three patches started with eight prey. Summing over all the patches, it follows that the expected total number of prey eaten (EN) in an experiment is

$$
\mathrm{E} N=24-8\left(\mathbf{1}^{\prime} \mathrm{e}^{\mathrm{A} \prime} \mathbf{1}\right)
$$

To calculate this, we used the fact that

$$
\mathrm{e}^{\mathbf{A} t}=\sum_{i=1}^{3} \mathbf{x}_{i} \mathbf{x}_{i}^{\prime} \mathrm{e}^{j i t}
$$

where the $\lambda_{i}$ are eigenvalues and the $\mathrm{x}$, are eigenvectors of the matrix A. It follows that

$$
\mathrm{E} N=24-8 \sum_{i=1}^{3} \mathrm{e}^{i{ }_{i}^{\prime}}\left(1^{\prime} \mathbf{x}_{i}\right)^{2}
$$

We found the eigenvalues and eigenvectors and substituted these values into equation A5 to arrive at the expected total number of prey eaten.

\section{ACKNOWLEDGMENTS}

We thank Dennis DeVries for his many contributions to this work. Richard Green, Tom Martin and an anonymous referee provided helpful comments on the manuscript. Equipment and travel for this work were funded by The Ohio Cooperative Fisheries Research Unit.

\section{REFERENCES}

Beard, T. D. 1982. Population Dyanamics of Young-of-the-year Bluegills. Madison, Wisconsin: Wisconsin Department of Natural Resources.

Charnov, E. L. 1976. Optimal foraging, the marginal value theorem. Theor. Pop. Biol, 9, 129-136.

Charnov, E. L., Orians, G. H. \& Hyatt, K. 1976. Ecological implications of resource depression. Am. Nat., 110, $247-$ 259.

Chesson, J. 1983. The estimation and analysis of preference and its relationship to foraging models. Ecology, 64, 1297-1304.

Cowie, R. J. 1977. Optimal foraging in great tits (Parus major). Nature, Lond., 268, 137-139.

Crowder, L. B. \& Cooper, W. B. 1982. Habitat structural complexity and the interaction between bluegills and their prey. Ecology, 63, 1802-1813.

Green, R. F. 1980. Bayesian birds: a simple example of Oaten's stochastic model of optimal foraging. Theor. Pop. Biol, 18, 244-256.

Green, R. F. 1984. Stopping rules for optimal foragers. Am. Nat., 123, 30-43.

Hartling, L. K. \& Plowright, R. C. 1979. Foraging by bumble bees Bombus atratus on patches of artificial flowers: a laboratory study. Can J. Zool, 57, 1866-1870.

Hollander, M. \& Wolfe, D. A. 1973. Nonparametric Statistical Methods. New York: John Wiley.

Howell, D. L. \& Hartl, D. L. 1980. Optimal foraging in Glossophagine bats: when to give up. Am. Nat., 115, 696704.

Iwasa, Y., Higashi, M. \& Yanamura, N. 1981. Prey distribution as a factor determining the choice of optimal 
foraging strategy. Am. Nat., 117, 710-723.

Johnson, N. L. \& Kotz, S. 1970. Distributions in Statistics: Continuous Univariate Distributions 1. Boston: Houghton Mifflin.

Keast, A. 1978. Feeding interrelation between age groups of pumpkinseed sunfish (Lepomis gibbosus) and comparisons with the bluegill sunfish (L. macrochirus). J. Fish. Res. Bd Can., 35, 12-27.

Kendall, M. G. 1962. Rank Correlation Methods. New York: Hafner.

Kotz, S., Johnson, N. L. \& Read, C. B. 1982. Encyclopedia of Statistical Sciences. Vol. I. New York: John Wiley.

Krebs, J. R. 1973. Behavioural aspects of predation. In: Perspectives in Ethology (Ed. by P. P. G. Bateson \& P. H. Klopfer), pp. 73-111. New York: Plenum Press.

Krebs, J. R. 1978. Optimal foraging: decision rules for predators. In: Behavioural Ecology: an Evolutionary Approach (Ed. by J. R. Krebs \& N. B. Davies), pp. 23-63. London: Sinauer.

Krebs, J. R., Ryan, J. C. \& Charnov, E. L. 1974. Hunting by expectation or optimal foraging? A study of patch use by chickadees. Anim. Behav., 22, 953-964.

Lima, S. L. 1983. Downy woodpecker foraging behavior: foraging by expectation and energy intake rate. Oecologia (Berl), 58, 232-237.

Lima, S. L. 1984. Downy woodpecker foraging behavior: efficient sampling in simple stochastic environments. Ecology, 65, 166-174.

McNair, J. N. 1982. Optimal giving-up times and the marginal value theorem. Am. Nat., 119, 511-529.

McNamara, J. 1982. Optimal patch use in a stochastic environment. Theor. Pop. Biol, 21, 269-288.

Mittelbach, G. G. 1981. Foraging efficiency and body size: a study of optimal diet and habitat use by bluegills. Ecology, 62, 1370-1386.

Murdoch, W. W. \& Oaten, A. 1975. Predation and population stability. Adv. Ecol. Res., 9, 1-131.

Nicholson, A. J. \& Bailey, V. A. 1935. The balance of animal populations. Proc. zool. Soc. Lond., 105, 551-598.

Pearson, E. S. \& Stephens, M. A. 1962. The goodness-of-fit tests based on $\mathrm{W}_{n}^{2}$ and $\mathrm{U}_{n}^{2}$. Biometrika, 49, $397-402$.

Pyke, G. H. 1978. Optimal foraging in hummingbirds: testing the marginal value theorem. Am. Zool, 18,739-752.

Seshadri, V., Csörgö, M. \& Stephens, M. A. 1969. Tests for the exponential distribution using Kolmogorov-type statistics. J. Roy. Stat. Soc, 31, 499-509.

Sokal, R. R. \& Rohlf, F. J. 1981. Biometry. San Francisco: W. H. Freeman.

Stein, R. A. \& Magnuson, J. J. 1976. Behavioral response of a crayfish to a fish predator. Ecology, 57, $751-761$.

Stephens, D. W. \& Charnov, E. L. 1982. Optimal foraging: some simple stochastic models. Behav. Ecol. Sociobiol, 10, 251-263.

Stewart-Oaten, A. 1982. Minimax strategies for a predator-prey game. Theor. Pop. Biol., 22, 410-424.

Townsend, C. R. \& Hildrew, A. G. 1980. Foraging in a patchy environment by a predatory net-spinning caddis larva: a test of optimal foraging theory. Oecologia (Berl), 47, 219--221.

Ware, D. M. 1973. Risk of epibenthic prey to predation by rainbow trout (Salmo gairdneri). J. Fish. Res. Bd Can., 30, 787-797.

Werner, R. G. 1967. Intralacustrine movements of bluegill fry in Crane Lake, Indiana. Trans. Am. Fish. Soc, 96, 416-420.

Ydenberg, R. C. 1984. Great tits and giving-up times: decision rules for leaving patches. Behaviour, 90, 1-24.

Zach, R. \& Falls, J. B. 1976. Do ovenbirds (Aves: Parulidae) hunt by expectation? Can. J. Zool, 54, 1894-1903. 